\title{
Utvikling og drift av Nettverk for Psykiatrisk Epidemiologi (NEPE)
}

\author{
Alv A. Dahl ${ }^{1}$, Marit Bjartveit Krüger ${ }^{2}$, Nils Håvard Dahl ${ }^{2}$, Eystein Stordal ${ }^{3}$ \\ og Arnstein Mykletun ${ }^{4}$ \\ ${ }^{I}$ Klinikk for psykiatri, Aker universitetssykehus HF, 0320 Oslo \\ ${ }^{2}$ Psykiatrisk klinikk, Helse Nord-Trøndelag HF, 7600 Levanger \\ ${ }^{3}$ Psykiatrisk klinikk, Helse Nord-Trøndelag HF, 7800 Namsos \\ ${ }^{4}$ Hemil-senteret, Psykologisk fakultet, Universitetet i Bergen, 5015 Bergen
}

\begin{abstract}
SAMMENDRAG
Fra 1995 og fremover har psykiske symptomer fått større plass i regionale helseundersøkelser ut fra erkjennelsen av psykiske lidelsers store betydning for folkehelsen. I denne artikkelen beskriver vi arbeidet med å etablere arbeidsgrupper for psykiatrisk epidemiologisk forskning for å publisere funn fra Helseundersøkelsen i NordTrøndelag (HUNT-2) og i Hordaland (HUSK). I den forbindelse har vi opprettet et Nettverk for Psykiatrisk Epidemiologi (NEPE) som omfatter grupper i Bergen, Levanger, Namsos, Oslo, Trondheim og Ålesund. NEPE har på disse stedene en rekke doktorgradstipendiater som allerede har publisert atskillig, og den første avhandlingen er nylig levert. Målsetningene til NEPE er å få fram kandidater til doktorgrad og professorkompetanse, holde regelmessige nettverksmøter, sørge for lokal veiledning, utnytte og etablere relevante databaser, og etablere internasjonale kontakter. Status for NEPE på disse feltene blir presentert ledsaget av en publikasjonsoversikt.
\end{abstract}

Dahl AA, Krüger MB, Dahl NH, Stordal E, Mykletun A. The Norwegian Network for Psychiatric Epidemiology (NEPE). Nor J Epidemiol 2003; 13 (1): 51-54.

\section{ENGLISH SUMMARY}

From 1995 and onwards mental problems have become a more prominent part of regional health studies in Norway based on the fact that mental disorders are a major health problem. In this paper we describe our efforts to establish research groups for psychiatric epidemiology in order to publish findings from the Health Study of Nord-Trøndelag County (HUNT-2) and Hordaland County (HUSK). We have established a Network for Psychiatric Epidemiology (NEPE) that includes groups in Bergen, Levanger, Namsos, Oslo, Trondheim and Ålesund. At these sites NEPE has research fellows who have published considerably, and the first dissertation has been submitted. The aims of NEPE are to guide candidates to doctoral theses and professoral competence, hold regular network meetings, give local supervision, use and establish relevant databases, and to work with international contacts. Status of NEPE in these areas is presented supplied by a publication overview.

\section{BAKGRUNN}

Systematiske undersøkelser i forhold til sentrale folkehelseproblemer har lange tradisjoner i Norge, først $i$ forhold til tuberkulose og senere hjerte-karsykdommer. Utover i 1990-årene ble det stadig klarere at psykiske lidelser også representerte et folkehelseproblem både ut $i$ fra sitt omfang og ved graden og varigheten av funksjonssvikt. "Global Burden of Disease"-undersøkelsen i regi av Verdens helseorganisasjon og Verdensbanken, fant at både i 1990 og i 2020 ville fem av de ti lidelsene som gav mest omfattende funksjonssvikt i industrilandene være psykiske $(1,2)$. Det ble derfor en helsepolitisk nødvendighet å ta med psykiske lidelser og symptombelastning i nye helseundersøkelser.

I befolkningen er de vanligste psykiske lidelsene depresjoner, angstlidelser, alkoholmisbruk og soma- tiseringslidelser (3). I Helseundersøkelsen i NordTrøndelag 1995-97 (HUNT-2) ble symptomer på de tre første lidelsene systematisk registerert. IDANTgruppen ble etablert i 1995 for å skaffe midler til analyserettigheter til angst og depresjon, som ble kartlagt med Hospital angst- og depresjonsskala (HADS) i HUNT-2. IDANT-gruppen består av fire personer hvorav tre fra Nord-Trøndelag: klinikkleder Marit Bjartveit Krüger, overlege Nils Håvard Dahl og overlege Eystein Stordal ved Psykiatrisk klinikk, Helse Nord-Trøndelag HF og professor Alv A. Dahl, Klinikk for psykiatri, Aker universitetssykehus HF. Virksomheten til IDANT-gruppen i Nord-Trøndelag er nylig beskrevet (4) og omfatter forskning ved Psykiatrisk klinikk, Helseforetaket Nord-Trøndelag, som omfatter både Levanger og Namsos.

I 1998 fikk IDANT-gruppen også delta med HADS i Helseundersøkelsen Hordaland 1998-2000 (HUSK). 
Dette datatilfanget, samt den store mengden problemstillinger omkring angst og depresjon i HUNT-2, ledet til etableringen av en arbeidsgruppe for psykiatrisk epidemiologi i Bergen. Denne gruppen har arbeidet med HADS-data både fra HUNT-2 og HUSK. Gruppen i Bergen fikk støtte av Norges forskningsråd over tre år (2000-2002) for å bygge opp epidemiologisk forskningskompetanse basert på HUNT-2 og HUSK. Utviklingen av gruppen i Bergen er nylig beskrevet (5). De engasjerte enhetene i Bergen er: Psykiatrisk klinikk, Haukeland sykehus, Psykiatrisk institutt, UiB, Seksjon for forebyggende medisin, Institutt for samfunnsmedisinske fag, UiB, Regionssenteret for barneog ungdomspsykiatri, HEMIL-senteret, Det psykologiske fakultet, UiB og Medisinsk fødselsregister.

Samarbeidet mellom enheter i Oslo, NordTrøndelag og Bergen var det opprinnelige grunnlaget for Nettverk for Psykiatrisk Epidemiologi (NEPE). NEPE har også analyserettigheter for screening på personlighetsforstyrrelser og sosial fobi i Helseundersøkelsen i Oslo (HUBRO). Disse data er fra mai 2002 gjort tilgjengelige for analyser. NEPE har fra 2001 hatt et økende samarbeid med Institutt for nevrovitenskap, NTNU, og NEPE har sammen med dette instituttet nylig innlevert forslag til psykiatri-kartlegging i HUNT-3. I denne sammenheng har NEPE også innledet et samarbeid med Nasjonalt folkehelseinstitutt. I tillegg har Institutt for nevrovitenskap fått en doktorgradsstipendiat (som blir med i NEPE) ved Psykiatrisk avdeling, Sykehuset Ålesund.

NEPE har til sammen 12 doktorander på gang, hvorav den første (Eystein Stordal) har innlevert sin avhandling i april 2003.

\section{Materiale}

NEPE har på det nåværende tidspunkt mulighet for å drive forskning på angst og depresjon ut fra følgende databaser:

- HUNT-1 1984-86, som er en fri base, der 74.977 $(88,1 \%)$ av de 87.285 personene som var 20 år og eldre deltok. Ut fra fire spørsmål om angst og depresjon har vi laget en indeks (ADI) som korrelerer rimelig godt med HADS i HUNT-2. Dette gir en mulighet for forskning med longitudinelt perspektiv på de 47.000 individene som deltok $\mathrm{i}$ både HUNT-1 og HUNT-2.

- HUNT-2 1995-97 der 66.140 (71,2\%) av de 92.936 personene som var eldre enn 20 år og eldre deltok. Her har NEPE betalt for og fått godkjent 30 prosjekter med angst/depresjon målt med HADS som avhengig variabel og diverse uavhengige variabler.

- HUSK 1997-99 der 38.587 personer i bestemte aldersklasser ble invitert, og der 25.634 (66,4\%) deltok. Her har NEPE fått med HADS i skjema 2, og det er hittil satt i gang relativt få prosjekter basert på denne basen, som er fri for godkjente prosjekter.
- HUBRO - helseundersøkelsen i Oslo har lagt ut sin database for analyser av godkjente prosjekter i 2002. NEPE har her rettigheter til screeningtester om sosial fobi og personlighetsforstyrrelser.

- Offisielle registre - det er søkt om eller innvilget kobling mellom overstående databaser og Medisinsk fødselsregister, sykehusregisteret i NordTrøndelag, Kreftregisteret, Dødsårsaksregisteret og Rikstrygdeverkets registre. Slike koblinger gir en rekke nye analysemuligheter.

- HUNT-3. Arbeidsgruppen for HUNT-3 ved NTNU har vært ledet av professor K. Gunnar Götestam. Den har foreslått at følgende psykiske forhold blir kartlagt i HUNT-3: Angst og depresjon (målt ved HADS), personlighet, kognitiv svikt/demens, traumer og traumereaksjoner, spilleavhengighet, spiseproblemer og mental helse. Vi vet ikke hvor mye av dette som vil komme med i HUNT-3, men det er klart at data fra både HUNT-2, HUNT-3, registerdata og biobank gir unike muligheter for årsaksforskning innen mental helse.

\section{Metode}

Det meste av det NEPE har produsert baserer seg på angst- og depresjonsdata ut fra HADS. Fordi denne testen er viktig for vårt arbeid har vi gjort en litteraturstudie basert på artikler med psykometriske data (Bjelland et al., 2002), og to psykometriske arbeider (Mykletun et al. 2001, Børve et al. 2003). Det vises i denne forbindelse til oversiktsartiklene $(4,5)$ og NEPEs publikasjonsliste (vedlegg).

\section{MÅLSETNINGER FOR NEPE}

1. Få fram personer til doktorgrad og professorkompetanse basert på emner innen psykiatrisk epidemiologi. Dette arbeidet er godt i gang med artikler som er publisert, i trykken, under vurdering eller under ferdigstillelse. Det vises i denne sammenheng til publikasjonslisten. Vi regner med at ca. 10 kandidater vil levere doktoravhandlinger $\mathrm{i}$ 2003-05 ved NTNU og UiB.

2. Etablere et stabilt nettverk for forskning innen psykiatrisk epidemiologi med regelmessige nettverksmøter. Hittil har det meste av NEPEs forskning foregått $\mathrm{i}$ atskilte miljøer i Namsos, Levanger, Bergen, Oslo og Trondheim. De hovedsakelige bindeleddene har vært de reisende veilederne (A.A. Dahl og A. Mykletun). Ellers har de ulike grupperingene møtt hverandre på epidemiologiske kongresser vesentlig takket være sponsing fra farmasøytisk industri. For etablering, stabilisering og videreutvikling trengs det mer fast etablert møteplass. På nettverksmøtene tenker vi oss at prosjekter fremlegges og planlegges, og at en drøfter saker av felles interesse for NEPEs medlemmer. Møtene tenkes holdt en gang i halvåret vekselvis i Bergen og på Værnes/Stjørdal. 
3. Skaffe og opprettholde de nødvendige ressurser for veiledning på statistikk og metode i psykiatrisk epidemiologi. De reisende veilederne har vært bindeleddene i NEPE gjennom sin veiledning i Namsos, Levanger og Bergen. Ved utvidelse av nettverket vil det være nødvendig med mer veiledningskompetanse særlig på data- og statistikksiden.

4. Rekruttere yngre fagfolk til forskning innen psykiatrisk epidemiologi. NEPE har en stamme av stipendiater og klinikere som forsker. Vi trenger imidlertid å rekruttere nye forskere med tanke på å styrke NEPE i Oslo, Trondheim og Bergen. Flere viderekommende studenter ved Det psykologiske fakultet, UiB har skrevet hovedoppgaver basert på data som NEPE disponerer. Minst en av disse har sagt seg interessert $\mathrm{i}$ å gå videre med et doktorgradsprosjekt.

5. Sikre utnyttelse av innsamlet og kommende datamateriale av relevans for psykiatrisk epidemiologi. NEPE har tatt kontakt med professor Kristian Tambs for å etablere samarbeid med Nasjonalt folkehelseinstitutt. Vi tenker oss at dette samarbeidet kan dreie seg om forskningsprosjekter knyttet til databaser som HUBRO og senere HUNT-3. HUNT forskningssenter i Verdal og Institutt for forebyggende helsearbeid, UiB (HUSK) har sentrale stillinger $\mathrm{i}$ forhold til den epidemiologiske forskningen som NEPE driver. Vi vil fortsette vårt gode samarbeid med disse institusjonene. Det kan også være grunn til å nevne NEPEs nære samarbeid med Det norske radiumhospital inklusive Kreftregisteret der HADS er i bruk ved en rekke psykososiale studier av kreftpasienter.

6. Internasjonale kontakter og presentasjoner. NEPE har ved flere anledninger vært i kontakt med professor Ronald C. Kessler ved Harvard University med sikte på felles prosjekter. Hittil har det ikke lykkes å få etablert slike, men vi holder kontakten med sikte på nærmere samarbeid i fremtiden. I april 2001 hadde NEPE besøk av professor Kathleen Merikangas i Bergen, Verdal og Levanger (tidligere Yale University, nå National Institutes of Health) slik at hun ble orientert om arbeidet vårt. Merikangas inviterte til felles prosjekter, uten at dette hittil har munnet ut i noe konkret. Ved at NEPE-medlemmer har lagt fram sine resultater på en rekke internasjonale kongresser gjennom de siste fem årene, begynner gruppen og arbeidene våre å bli kjent. Vi mener at dette vil øke sjansene for gode internasjonale samarbeidsprosjekter gjerne med EU-midler. Tidligere har Alv A. Dahl sittet i styret for Nordic Association for Psychiatric Epidemiology (NAPE), og for tiden sitter Eystein Stordal der.

\section{OPPSUMMERING OG KONKLUSJON}

Vi har fra slutten av 1995 lagt grunnlag for et fungerende Nettverk for psykiatrisk epidemiologi (NEPE) som hovedsakelig driver forskning basert på data fra HUNT og HUSK. Medlemmene av nettverket har kommet godt i gang med forskning, og en velfungerende veiledningsordning er etablert. Det vises i denne forbindelse til oversiktsartikler $(4,5)$. Når det gjelder publikasjoner vises det til vedlagte liste. Vi regner med at ti av kandidatene vil levere avhandlinger innen utgangen av 2005. Ut fra vår nåsituasjon vil vi arbeide med å:

- Fortsette og utvide veiledningsordningen

- Avholde halvårlige nettverksmøter

- Skaffe nye databaser.

På denne måten tenker NEPE seg å nå sitt hovedmål som er å styrke psykiatrisk epidemiologi som forskningsfelt i Norge gjennom bygging og drift av et forskningsnettverk.

\section{REFERANSER}

1. Murray CJL, Lopez AD. Global mortality, disability, and the contribution factors: Global Burden of Disease Study. Lancet 1997; 349: 1436-42.

2. Murray CJL, Lopez AD. Alternative projections of mortality and disability by cause 1990-2020: Global Burden of Disease Study. Lancet 1997; 349: 1498-504.

3. Kringlen E, Torgersen S, Cramer V. A Norwegian epidemiological study. Am J Psychiatry 2001; 158: 1091-8.

4. Dahl AA, Bjartveit Krüger M, Dahl, NH, Stordal E, Mykletun A. Angst, depresjon og psykiatrisk epidemiologisk forskning i Nord-Trøndelag. Norsk Epidemiologi 2002; 12: 347-54.

5. Dahl AA, Bjelland I, Moe TJ, Mykletun A, Roness A. Etablering av en gruppe for psykiatrisk epidemiologisk forskning i Bergen. Norsk Epidemiologi 2002; 12: 355-60.

\section{NEPE-PUBLIKASJONER FRA HUNT-2 OG HUSK 1999-2003}

1. Bjelland I, Dahl AA. Angst og depresjon - en vanlig blanding. Tidsskr Nor Lageforen 1999; 119: $3277-80$.

2. Sanne B, Dahl AA, Tell GS. Depresjon - samfunnsøkonomiske perspektiver. Tidsskr Nor Laegeforen 2000; 121: 590-96. 
3. Stordal E, Dahl NH, Krüger MB, Krüger Ø, Mykletun A, Dahl AA. Depression in relation to age and gender in the general population: the Nord-Trøndelag Health Study (HUNT) Acta Psychiatr Scand 2001; 104: 210-6.

4. Mykletun A, Stordal E, Dahl AA. The Hospital Anxiety and Depression Scale (HAD): factor structure, item analyses, and internal consistency in a large population. Br J Psychiatry 2001; 179: 540-4.

5. Bjelland I, Dahl AA, Tangen Haug T, Neckelmann D. The validity of The Hospital Anxiety and Depression Scale: an updated literature review. J Psychosom Res 2002; 52: 69-77.

6. Tangen Haug T, Mykletun A, Dahl AA. The prevalence of nausea in the community: psychological, social and somatic factors. Gen Hosp Psychiatry 2002; 24: 81-6.

7. Tangen Haug T, Mykletun A, Dahl AA. Is anxiety and depression related to gastrointestinal symptoms in the general population? Scand J Gastroenterol 2002: 37: 294-8.

8. Engum A, Bjøro T, Mykletun A, Dahl AA. An association between depression, anxiety, and thyroid function - a clinical fact or an artefact? Acta Psychiatr Scand 2002; 106: 27-34.

9. Dahl AA, Mykletun A, Stordal E. Factor structure of the Hospital Anxiety and Depression (HAD) scale. $B r J$ Psychiatry 2002; 181: 165-6.

10. Wenzel HG, Haug TT, Mykletun A, Dahl AA. A population study of anxiety and depression among persons who report whiplash traumas. $J$ Psychosom Res 2002; 53: 831-5.

11. Bjørnelv S, Mykletun A, Dahl AA. The influence on the prevalence of eating problems in an adolescent population. J Eating Weight Disord 2002; 7: 284-92.

12. Stordal E, Mykletun A, Dahl AA. The association between age and depression in the general population: a multivariate examination. Acta Psychiatr Scand 2003; 107: 132-41.

13. Zwart J-A, Hagen K, Ødegård KJ, Dahl AA, Bovim G, Stovner LJ. Anxiety and depression associated with headache frequency. The Nord-Trøndelag Health Study. Eur J Neurol 2003; 10: 147-52.

14. Bjelland I, Tell GS, Vollset SE, Refsum H, Ueland PM. Folate, cobalamin, homocysteine and MTHFR $677 \mathrm{C} \rightarrow \mathrm{T}$ polymorphism in anxiety and depression. The Hordaland Homocysteine Study. Arch Gen Psychiatry 2003; 60: 618-26.

\section{ARBEIDER I TRYKKEN}

15. Berle JØ, Dahl AA, Holsten F, Mykletun A, Aare TF. Screening for postnatal depression. Assessment of risk factors and validation of the Norwegian version of the Edinburgh Postnatal Depression Scale (EPDS). J Affect Disord.

16. Stordal E, Mykletun A, Bjelland I, Dahl AA. Anxiety and depression in individuals with somatic health problems. The Nord-Trøndelag Health Study (HUNT). Scand J Primary Health Care.

17. Sanne B, Mykletun A, Dahl AA, Moen BE, Tell GS. Occupational differences in levels of anxiety and depression. The Hordaland Health Study. J Occup Environ Med.

18. Sanne B, Mykletun A, Moen BE, Dahl AA, Tell GS. Farmers are at risk for anxiety and depression. The Hordaland Health Study. Occup Med.

\section{ARBEIDER INNSENDT TIL VURDERING:}

19. Børve TA, Gjestad R, Bjerkeset O, Dahl AA, Bjartveit Krüger M, Dahl NH, Stordal E. Hospital anxiety and depression scale: confirmatory factor analysis and psychometric properties in a Norwegian population. $J$ Affect Dis.

20. Bjelland I, Stordal E, Mykletun A, Dahl AA. Co-dimensionality of anxiety and depression in a large population. Psychother Psychosom.

21. Engum A, Bjøro T, Mykletun A, Dahl AA. A population-based study of the relation between depression, anxiety and autoimmune thyroiditis. Scand J Clin Lab Invest.

22. Stordal E, Morken G, Mykletun A, Neckelmann D, Dahl AA. Monthly variation in prevalences of anxiety disorder and depression in the general population at 63-65 North: The HUNT Study. Am J Psychiatry.

23. Berle JØ, Mykletun A, Daltveit AK, Holsten F, Dahl AA. Neonatal outcomes in offspring of women with depression and anxiety during pregnancy: a population based, comparative register study. Br J Psychiatry.

24. Sanne B, Torp S, Mykletun A, Dahl AA. The Swedish Demand-Control-Support Questionnaire (DCSQ): factor structure, item analyses and internal consistency in a large population. Work Stress.

27. Neckelmann D, Mykletun A, Dahl AA. Insomnia as a risk factor for developing anxiety and depression. A prospective epidemiological study. Am J Psychiatry. 